\title{
Capsule Commentary on Davydow et al., Neuropsychiatric Disorders and Potentially Preventable Hospitalizations in a Prospective Cohort Study of Older Americans
}

\author{
Timothy F. Platts-Mills, MD, Msc \\ Department of Emergency Medicine, University of North Carolina at Chapel Hill, Chapel Hill, NC, USA.
}

J Gen Intern Med 29(10):1390

DOI: $10.1007 / \mathrm{s} 11606-014-2930-\mathrm{x}$

(c) Society of General Internal Medicine 2014

$\mathrm{T}$ his study by Davydow et al. ${ }^{1}$ uses the Health and Retirement Study to examine the relationship between depression and cognitive impairment and preventable hospitalizations among older adults. The investigators find that older adults with these neuropsychiatric disorders, and especially those with both depression and cognitive impairment, have higher rates of hospital admission for ambulatory care sensitive conditions and higher rates of readmission for a number of common conditions. They conclude that there is a need to develop strategies to reduce hospitalizations in older adults with depression and cognitive impairment.

Although it is true that, all other things equal, reducing hospitalizations is good, there is some risk in pursuing this as a goal. A better goal is to improve the value of healthcare delivered to these patients, with value defined as health outcomes achieved per dollar spent. ${ }^{2-4}$ Hospitalizations are easy to measure and an important component of health care costs. But reducing hospitalizations only improves value if outcomes also improve (or remain unchanged) and the cost of the intervention does not exceed the cost savings from reduced hospitalizations.

Two important outcomes, quality of life and independence, are identified by the authors. For older adults with depression, another outcome might be depressive symptoms. For those with cognitive impairment, other outcomes might be physical and cognitive function. For both groups, costs should include both direct medical expenditures as well as caregiver costs.

The authors have provided a service by bringing to our attention the presence of a group of older adults at risk for generating large health care costs. But the right next step is not to develop interventions to reduce hospitalizations or some other measure of cost. The right next step is the development of interventions to improve value. The move from volume to value in US healthcare is underway ${ }^{5}$; researchers should embrace this shift by conducting studies that identify value, not just costs, as the primary outcome.

Conflict of Interest: The author has no conflict with any of the material in this manuscript.

Corresponding Author: Timothy F. Platts-Mills, MD, Msc; Department of Emergency Medicine, University of North Carolina at Chapel Hill, 170 Manning Drive CB\#7594, Chapel Hill, NC 27599-7594, USA (e-mail: tplattsm@med.unc.edu).

\section{REFERENCES}

1. Davydow DS, Zivin K, Katon WJ, et al.Neuropsychiatric disorders and potentially preventable hospitalizations in a prospective cohort study of older Americans. J Gen Intern Med. 2014;SPI:2916.

2. Porter ME. What is value in health care? N Engl J Med. 2010;363:247781.

3. Porter ME, Lee TH. The strategy that will fix health care. Harv Bus Rev 2013:1-19.

4. Platts-Mills TF, Glickman Sw. Measuring the value of a senior emergency department: making sense of health outcomes and health costs. Ann Emerg Med 2014;63.

5. VanLare JM, Conway PH. Value-based purchasing-national programs to move from volume to value. N Engl J Med. 2012;367:292-5.

Published online July 4, 2014 